TRIADIK

ISSN (print): 0853-8301; ISSN (online): 2745-777X

Available online at https://ejournal.unib.ac.id/index.php/triadik

DOI: https://doi.org/10.33369/triadik.v20i1.16464

page: $1-9$

\title{
PENGARUH LAYANAN BIMBINGAN KELOMPOK DENGAN TEKNIK PERMAINAN (GAME) UNTUK MENINGKATKAN KECERDASAN EMOSIONAL SISWA KELAS VIII SMP NEGERI 18 KOTA BENGKULU
}

\author{
Zili Agustian Pratama, Syahriman, Vira Afriyati \\ Universitas Bengkulu
}

Korespondensi: ziliaagustianpratama@gmail.com

\begin{abstract}
Abstrak
Latar belakang penelitian ini dilaksanakan pada siswa kelas VIII yang masih kurang dalam segi mengontrol emosi, mudah marah, tidak berempati serta kurang percaya diri. Penelitian ini bertujuan untuk mendeskripsikan pengaruh layanan bimbingan kelompok dengan teknik permainan (game) untuk meningkatkan kecerdasan emosional siswa kelas VIII 5 SMP Negeri 18 Kota Bengkulu. Penelitian ini merupakan penelitian eksperimen dengan desain one grup pretest dan postest. Teknik yang digunakan yaitu purposive sampling, dimana sampel pada penelitian ini dipilih 10 orang siswa. Sebelum dilaksanakannya treatment kecerdasaan emosional siswa tergolong rendah dan setelah diadakannya treatment kecerdasan emosionalnya tegolong tinggi. Dilihat dari hasil pengujian hipotesis dengan hasil uji t -7.193 nilai sig sebesar $0,000(<0,005)$ maka Ho ditolak. Hasil penelitian ini menujukan adanya pengaruh yang signifikan terhadap layanan bimbingan kelompok dengan teknik permainan (game) untuk meningkatkan kecerdasaan emosional siswa kelas VIII 5 SMP Negeri 18 Kota Bengkulu.
\end{abstract}

Kata kunci: layanan bimbingan kelompok, teknik permainan (game), kecerdasan emosional

\begin{abstract}
The background of this research was carried out on grade VIII students who were still lacking in controlling emotions, irritability, empathy and lack of self-confidence. This study aims to describe the effect of group guidance services using game techniques to improve the emotional intelligence of grade VIII 5 students of SMP Negeri 18 Bengkulu City. This research is an experimental research with one group pretest and posttest design. The technique used is purposive sampling, where the sample in this study was selected 10 students, before the implementation of the treatment of students' emotional intelligence is classified as low and after the treatment of emotional intelligence is high. Judging from the results of hypothesis testing with the t-test results of -7.193 sig value of $0.000(<0.005)$ then Ho is rejected. The results of this study indicate that there is a significant influence on group guidance services with game techniques to improve the emotional intelligence of grade VIII 5 students of SMP Negeri 18 Bengkulu City.
\end{abstract}

Keywords: group guidance services, game techniques, emotional intelligence 


\section{Pendahuluan}

Pendidikan merupakan usaha sadar untuk mempengaruhi peserta didik agar mampu mengembangkan dan mengaktualisasikan potensi-potensi yang dimiliki agar mampu menjalani hidup dengan sebaik-baiknya (Utama, 2011:1). Artinya pendidikan penting bagi setiap orang, dengan adanya pendidikan kita dapat mengembangkan potensi yang dimiliki, serta mendapatkan ilmu pengetahuan yang luas.

Selain itu pendidikan juga sebagai sarana dalam pembelajaran untuk meningkatkan potensi yang ada di dalam diri seseorang, dengan adanya pendidikan potensi yang ada di dalam diri siswa akan tersalurkan. UndangUndang No. 20 Tahun 2003 (dalam Utama, 2011 :2) "Pendidikan adalah usaha sadar dan terencana untuk mewujudkan suasana belajar dan proses pembelajaran agar peserta didik secara aktif mengembangkan potensi dirinya untuk memiliki kekuatan spritual keagamaan, pengendalian diri, kepribadian, kecerdasan, akhlak mulia, serta keterampilan yang diperlukan dirinya, masyarakat, bangsa dan negara". Jadi siswa dituntut untuk dapat mengembangkan potensi dirinya serta dapat mewujudkan suasana belajar dengan baik, agar proses dan tujuan pembelajran tercapai sesuai dengan apa yang diinginkan.

Pembelajaran juga akan membentuk sikap dan kepercayaan pada peserta didik yang nantinya akan menjadikan peserta didik mampu menguasai materi yang diajarkandengan baik, serta dapat mengkaitkan proses pembelajaran dengan kehidupan sehari-hari sehingga peserta didik mampu berfikir lebih luas. Pembelajaran adalah proses interaksi peserta didik dan pendidik, dengan bahan pembelajaran, metode penyampaian, strategi pembelajaran dan sumber belajar dalam suatu lingkungan belajar (Pane \& Darwis Dasopang, 2017: 334).

Kecerdasan emosional merupakan kapasitas manusiawi yang dimiliki seseorang dan sangat berguna untuk menghadapi, memperkuat diri, mengubah emosi yang tidak menyenangkan menjadi suatu hal yang wajar untuk diatasi Haryanto (dalam Melianasari, 2016: 312). Kecerdasan emosional yang baik dapat menentukan keberhasilan individu dalam membangun kesuksesan karir maupun sosialnya Golemen (dalam Lestari, 2012: 89). Oleh karena itu, setiap orang memiliki kecerdasan emosional yang berbeda-beda dari kecerdasan emosionalnya rendah sampai yang tinggi, selain itu kecerdasan emosional yang tinggi sangatlah penting untuk kehidupan sehari-hari seperti bisa mengontrol emosi, memotivasi diri, percaya diri, dan empati.

Seperti penelitian terdahulu yang pernah diteliti oleh Desi Susilowati pada tahun 2016 Universitas Lampung yang membahas mengenai "Penggunaan Layanan Bimbingan Kelompok Untuk Meningkatkan Kecerdasan Emosi Siswa Kelas VIII Smp Negeri 01 Tanjung Sari Kabupaten Lampung Selatan". Pada penelitian tersebut melihat apakah layanan bimbingan kelompok dapat dipergunakan untuk meningkatkan kecerdasan emosi siswa yang rendah atau tidak, sedangkan pada penelitian ini membahas mengenai adakah pengaruh layangan bimbingan kelompok dengan teknik permainan untuk meningkatkan kecerdasan emosional siswa. Hal ini bisa kita amati bahwa anak SMP khususnya di kelas VII yang sekarang sudah naik ke kelas VIII dalam tahap proses peralihan remaja masih senang dengan berbagai 
permainan yang disajikan, dengan mengadakan permainan itulah kita dapat melihat apakah siswa tersebut dapat mengontrol, mempertahankan bahkan meningkatkan kecerdasan emosional dilingkungannya khususnya didalam kelompok antar siswa tersebut.

Berdasarkan fakta yang ada dilapangan pada saat melaksanakan magang II di SMP Negeri 18 Kota Bengkulu pada bulan September-November 2019 peneliti melihat masih banyak siswa yang kurang dalam segi mengontrol emosi, belum bisa mengelolah emosinya secara lebih efektif, mereka mudah berselisih dengan teman, mudah marah, tidak berempati, serta kurang percaya diri, sedangkan kecerdasaan emosional ini sangat penting diterapkan dikehidupan sehari-hari seperti dalam pengambilan keputusan, bisa merasakan empati, peduli terhadap orang lain, serta dapat membina hubungan dengan orang lain. Oleh karena itu dalam penelitian ini peneliti ingin meneliti mengenai kecerdasaan emosional siswa kelas VIII 5 di SMP Negeri 18 Kota Bengkulu yang kecerdasaan emosionalnya masih rendah, mereka masih membawa sifat atau tingkah laku pada saat masih duduk di sekolah dasar (SD), maka dari itu peneliti ingin mengadakan bimbingan kelompok agar kecerdasan emosional siswa tersebut meningkat.

Bimbingan kelompok merupakan salah satu jenis layanan yang dapat membantu masalah-masalah yang berhubungan dengan tumbuh kembangnya kepribadian siswa, di samping jenis layanan lainnya (Amri, Syahniar, \& Nirwana, 2016: 75). Tujuan bimbingan kelompok yaitu bisa berbicara di depan orang banyak, belajar menghargai pendapat orang lain, mampu mengendalikan diri dan menahan emosi (gejolak kejiwaan yang bersifat negatif), dapat bertenggang rasa, dan bertanggung jawab atas pendapat yang dikemukakannya Prayitno (dalam Hidayati, Mulawarman, \& Awalya, 2017: 28). Dengan diadakannya bimbingan kelompok diharapkan siswa terbantu dalam pengembangan perasaan, pikiran, wawasan dan sikap untuk meningkatkan kecerdasan emosional dengan teknik permainan (game).

Bermain adalah setiap kegiatan yang dilakukan untuk kesenangan yang ditimbulkannya, tanpa mempertimbangkan hasil akhir, terdiri atas tanggapan yang diulang sekedar untuk kesenangan fungsional Hurlock (dalam Utama, 2011: 3). Permainan adalah gejala manusia yang merupakan aktivitas dinamika manusia yang dibudayakan (Sukintaka dalam Susanto, 2017: 100). Permainan memiliki aturan yang telah ditentukan sebagai contoh aturan permainan yang akan dilakukan dan tata cara permainannya (Susanto, 2017: 100). Penggunaan teknik permainan agar peserta didik dapat merasakan langsung manfaat bimbingan kelompok serta membuat bimbingan kelompok tersebut menjadi lebih efektif dan menyenangkan. Dalam menyelenggarakan permainan kelompok itu harus selalu diingat bahwa tujuan permainan itu ialah untuk penghangatan dan pengakraban.

Berdasarkan dari uraian latar belakang tersebut, maka peneliti ingin meneliti tentang "Pengaruh Layanan Bimbingan kelompok dengan Teknik permainan (Game) untuk meningkatkan kecerdasan emosional siswa kelas VIII 5 Smp Negeri 18 kota Bengkulu”.

Berdasarkan permasalahan di atas, maka rumusan masalah dalam penelitian ini adalah, bagaimana kecerdasan emosional siswa kelas VIII 5 SMP Negeri 18 Kota Bengkulu sebelum diberikan bimbingan kelompok, bagaimana kecerdasaan emosional siswa kelas VIII 5 SMP Negeri 18 Kota Bengkulu setelah diberikan bimbingan kelompok dan bagaimana pengaruh 
bimbingan kelompok dengan teknik permainan (game) untuk meningkatkan kecerdasan emosional siswa kelas VIII 5 SMP Negeri 18 Kota Bengkulu.

\section{Metode Penelitian}

Penelitian ini menggunakan desain satu kelompok pretest-posttest (one group pretest-posttest design) dan kelompok tersebut dilakukan dua kali pengukuran. Adapun populasi pada penelitian ini yaitu siswa kelas VIII 5 SMP Negeri 18 Kota Bengkulu yang berjumlah 29 orang dan sampel dalam penelitian ini menggunakan purposive sampling sebanyak 10 orang siswa yang kecerdasaan emosionalnya masih rendah. Pengambilan subjek dalam penelitian ini peneliti memberikan angket (pretest) sebelum diberikan layanan bimbingan kelompok dengan teknik permainan dan (posttest) setelah diberikan layanan. Teknik pengumpulan data dalam penelitian ini yaitu angket skala likert, skala yang digunakan adalah mulai dari satu sampai empat, yang memiliki kriteria yaitu, sangat mampu (SM), mampu (M), tidak setuju (TM), sangat tidak mampu (STM).

Menurut Sugiyono (2016: 121) uji validitas instrument yang valid berarti alat ukur yang digunakan untuk mendapatakan data (mengukur) itu valid. Adapun validitas isi yang dilakukan oleh para ahli atau dosen bimbingan dan konseling yaitu (1) Dr. Hadiwinarto, M. Psi. (2) Dr. Wasidi, M. Pd. dan (3) Dr. Yessy Elita, S. Psi. M.A, lalu diberikan kepada 29 responden dan diolah menggunakan bantuan aplikasi computer yaitu SPSS versi 24.0.

Menurut Sugiyono (2016: 26) pengujian reliabilitas instrumen dengan menggunakan rumus Alpha Cronbach. Penggunaan rumus Alpha Cronbach karena instrumen penelitian ini berbentuk angket. Berdasarkan uji reliabelitas diperoleh alpha cronbach sebesar 0.911>0.7. Maka dapat disimpulkan bahwa instrumentasi tersebut dapat dipercaya atau sudah sangat baik digunakan dalam suatu penelitian.

Penelitian ini menggunakan uji t dengan teknik analis data dengan metode analisis data ststistik compare means dengan rumus paired samples T-test pada SPSS 24.0. menggunakan rumus uji-t karena sampel dalam penelitian ini kurang dari 30. Skala yang digunkan untuk mengukur kedua variabel tersebut adalah skala ordinal. Skala tersebut dimasukan kedalam jenjang - jenjang atau rangking, sehingga dapat diukur dengan menggunakan statistika non parametric dengan menggunakan analisis korelasi Rank Spearman, yang menggunakan rumus sebagai berikut:

$$
\mathrm{t}=r_{s} \sqrt{\frac{N-2}{1-r_{s}^{2}}}
$$

Kendall (dalam Sidney Siegel, 1956: 212)

Keterangan:

$r_{s}=$ Koefisien korelasi rank spearman

$\mathrm{t} \quad=$ Distribusi student dengan derajat kebebasan $\mathrm{dk}=\mathrm{n}-2$

$\mathrm{N}$ = Banyak sampel

Adapun keranga berfikir pada penelitian ini adalah : 


\section{Gambar 1}

\section{Kerangka Berpikir}

\begin{tabular}{|c|c|c|c|}
\hline $\begin{array}{c}\text { Bimbingan } \\
\text { tentang Kecerdasan } \\
\text { Emosional (Rendah) } \\
\text { Kelompok Dengan } \\
\text { Teknik Permainan }\end{array}$ & $\rightarrow$ & $\begin{array}{c}\text { Pemahaman siswa } \\
\text { tentang Kecerdasan } \\
\text { Emosional } \\
\text { (Meningkat) }\end{array}$ \\
\hline
\end{tabular}

Penjelasan dari kerangka berpikir diatas yaitu kecerdasan emosional siswa kelas VIII 5 yang masih rendah kemudian diberikan treatment sebagai bentuk bantuan melalui layanan bimbingan dengan teknik permainan, setelah diberikan perlakuan diharapkann kecerdasan emosional siswa meningkat.

\section{Hasil dan Pembahasan}

Deskripsi data merupakan upaya untuk memperoleh pemahaman lebih lanjut tentang variabel penelitian, yang bertujuan memberikan gambaran secara umum hasil penelitian yang berkaitan dengan variabel (Bimbingan kelompok dengan teknik permainan (game) dan variabel (Meningkatkan kecerdasan emosional). Maka, dapat dihitung interval pengukuran kecerdasan emosional sesuai dengan rumus perhitungan skala interval yang dijelaskan oleh Nurkanca (2000: 89) sebagai berikut:
a. Sangat Tinggi
$=\mathrm{M}+1,5(\mathrm{SD})=70+1.5(14)=91$
b. Tinggi
$=\mathrm{M}+0,5(\mathrm{SD})=70+0.5(14)=77$
c. Sedang
$=\mathrm{M}$
$=70$
d. Rendah
$=\mathrm{M}-0,5(\mathrm{SD})=70-0.5(14)=63$
e. Sangat Rendah
$=\mathrm{M}-1,5(\mathrm{SD})=70-1.5(14)=49$

Maka kategori interval pemerolehan skor pengaruh layanan bimbingan kelompok dengan Teknik permainan (game) pre-test sebagai berikut:

Tabel 1

Distribusi Frekuensi Kecerdasaan Emosional sebelum Treatment Kategori Jumlah Siswa Presentase

\begin{tabular}{ccc}
\hline Sangat Tinggi $(>149)$ & 0 & $0 \%$ \\
Tinggi $(77-90)$ & 1 & $10 \%$ \\
Sedang $(70-76)$ & 2 & $20 \%$ \\
Rendah $(63-69)$ & 6 & $60 \%$ \\
Sangat Rendah $(<62)$ & 1 & $10 \%$ \\
Total & 10 & $100 \%$
\end{tabular}

Berdasarkan Tabel 1 sebelum diberikan layanan bimbingan kelompok dengan teknik permainan (game) dapat disimpulkan bahwa siswa yang memiliki kecerdasan emosional sangat tinggi dengan skor $\geq 91$ berjumlah 0 orang (0\%), kategori tinggi dengan skor 77 - 90 berjumlah 1 orang (10\%), kategori sedang dengan skor 70 - 76 berjumlah 2 orang (20\%), kategori rendah dengan skor 63 - 69 berjumlah 6 orang (60\%), dan kategori sangat rendah 
dengan skor $\leq 62$ berjumlah 1 orang (10\%). Maka dapat disimpulkan bahwa sebelum diberikan layanan bimbingan kelompok dengan teknik permainan (game), banyak siswa kelas VIII 5 SMP Negeri 18 Kota Bengkulu memiliki kecerdasan emosional tergolong sedang, rendah, dan sangat rendah.

Tabel 2

\section{Distribusi Frekuensi Kecerdasaan Emosional setelah Treatment}

\begin{tabular}{ccc}
\hline Kategori & Jumlah Siswa & Persentase \\
\hline Sangat Tinggi & 5 & $50 \%$ \\
$(>149)$ & 5 & $50 \%$ \\
Tinggi (77-90) & 0 & $0 \%$ \\
Sedang (70-76) & 0 & $0 \%$ \\
Rendah (63-69) & 0 & $0 \%$ \\
Sangat Rendah $(<$ & 10 & $100 \%$
\end{tabular}

62)

Total

Berdasarkan Tabel 2 dapat diketahui adanya peningkatan kecerdasan emosional siswa yang semula berada dikategori sedang, rendah, dan sangat rendah menjadi 5 siswa berada dalam kategori yang tinggi dan 5 siswa dikategori sangat tinggi.

Berikut perbandingan skor dan mean sepuluh orang sampel yang memiliki skor terendah saat pre-test dan post-test setelah diberikan treatment dapat dilihat pada tabel dibawah ini:

Tabel 3

Peningkatan skor kecerdasaan emosional

\begin{tabular}{ccccccc}
\hline No & $\begin{array}{c}\text { Kode } \\
\text { Siswa }\end{array}$ & $\begin{array}{c}\text { Skor } \\
\text { Pre- } \\
\text { Test }\end{array}$ & Kategori & $\begin{array}{c}\text { Skor } \\
\text { Post } \\
\text { Test }\end{array}$ & Kategori & $\begin{array}{c}\text { Skor } \\
\text { Peningkata } \\
\text { n }\end{array}$ \\
\hline 1 & BMI & 59 & Sangat & 84 & Tinggi & 25 \\
2 & SDA & 64 & Rendah & 98 & Sangat Tinggi & 34 \\
3 & AR & 65 & Rendah & 93 & Sangat Tinggi & 28 \\
4 & SB & 66 & Rendah & 86 & Tinggi & 20 \\
5 & FA & 66 & Rendah & 100 & Sangat Tinggi & 34 \\
6 & DA & 69 & Rendah & 93 & Sangat Tinggi & 24 \\
7 & AK & 69 & Rendah & 81 & Tinggi & 12 \\
8 & M.HMA & 72 & Rendah & 88 & Tinggi & 16 \\
9 & EOS & 75 & Sedang & 99 & Sangat Tinggi & 24 \\
10 & FJS & 79 & Sedang & 82 & Tinggi & 3 \\
& & 684 & Tinggi & 964 & & \\
& & 79 & & 100 & &
\end{tabular}

Jumlah

Tertinggi

Terendah

Mean 
Berdasarkan tabel 3 disimpulkan bahwa meningkatnya skor kecerdasaan emosional siswa kelas VIII 5 SMP Negeri 18 Kota Bengkulu yang diperoleh skor dari 10 orang siswa sebelum dan sesudah diberikan layanan bimbingan kelompok terjadi kenaikan dengan rata-rata nilai sebelum diberikan layanan yaitu 69 yang termasuk kategori rendah, setelah diberikan layanan bimbingan kelompok terjadi kenaikan dengan nilai rata-rata 91 yang termasuk kategori sangat tinggi. Selain itu terdapat dua orang yang peningkatan post testnya sangat tinggi yaitu 34 karena selama pelaksanaan bimbingan kelompok klien sangat aktif dan sudah memahami mengenai kecerdasaan emosional dan terdapat satu orang yang peningkatan posttestnya sangat rendah karena selama pelaksanaan bimbingan kelompok siswa tersebut kurang aktif.

Berdasarkan tabel 3 diketahui bahwa terjadi peningkatan kecerdasan emosional pada siswa setelah diberikan treatment berupa bimbingan kelompok dengan teknik permainan (game). Pada tabel diatas menunjukkan perbedaan skor dan mean sebelum dan sesudah diberikan treatment, yang diketahui pada skor pre-test sebanyak 10 orang siswa yang kategori rendah dengan rata-rata mean yaitu 69.

Adapun siswa yang mengalami peningkatan tersebut yaitu, yang pertama BMI yang mendapatkan skor pre-test 59 kategori sangat rendah menjadi 84 setelah diberikan post-test menjadi kategori tinggi, yang kedua yaitu SDA yang mendapatkan skor pre-test 64 kategori rendah menjadi 98 setelah diberikan post-test menjadi kategori sangat tinggi. Lalu, yang ketiga AR yang mendapatkan skor pre-test 65 kategori rendah menjadi 93 setelah diberikan post-test menjadi kategori sangat tinggi, yang keempat SB yang mendapatkan skor pre-test 66 kategori rendah menjadi 86 setelah diberikan post-test menjadi kategori tinggi. Yang kelima FA yang mendapatkan skor pretest 66 kategori rendah menjadi 100 setelah diberikan post-test menjadi kategori sangat tinggi.

Kemudian, yang keenam DA yang mendapatkan skor pre-test 69 kategori rendah menjadi 93 setelah diberikan post-test menjadi kategori sangat tinggi, yang ketujuh AK yang mendapatkan skor pre-test 69 kategori rendah menjadi 81 setelah diberikan post-test menjadi kategori tinggi. Setelah itu yang kedelapan MHMA yang mendapatkan skor pre-test 72 kategori sedang menjadi 88 setelah diberikan post-test menjadi kategori tinggi, sedangkan EOS mendapatkan skor pre-test 75 kategori sedang menjadi 99 setelah diberikan post-test menjadi kategori sangat tinggi, dan yang terakhir FJS yang mendapatkan skor pre-test 79 kategori tinggi menjadi 82 setelah diberikan post-test menjadi kategori tingi. Hasil penelitian ini dapat disimpulkan bahwa terjadi peningkatan kecerdasan emosional siswa yang ditunjukan dengan mean 69 pada saat pre-test menjadi 91 setelah post-test. Berdasarkan Tabel 5 dapat dilihat bahwa Cronbach's Alpha sebesar 0,911, itu artinya angket tersebut masuk ke dalam kategori reliabilitas yang baik.

Hasil uji hipotesis yang telah dilakukan, terjadi peningkatan kecerdasaan emosional siswa pada pre-test dan post-test melalui analisis $T$ test yang menunjukan nilai sig (2-tailed) sebesar 0.000. Hal ini menunjukan bahwa layanan bimbingan kelompok dengan teknik permainan (game) dapat meningkatkan kecerdasaan emosional siswa. Hasil ini menunjukan signifikansi $0,000<0,05$ yang berdasarkan kriteria penerimaan atau penolakan hipotesis Ho ditolak dan $\mathrm{Ha}$ diterima, 
Adapun hasil uji hipotesis yang diperoleh menggunakan SPSS versi 24 . Dengan menggunakan uji t adalah sebagai berikut:

Tabel 4

Paired Sample T-test

\begin{tabular}{lr}
\hline $\mathrm{T}$ & Posttest-pretest \\
\hline Sig. (2-tailed) & -7.193 \\
& 0.000
\end{tabular}

Berdasarkan hasil perhitungan pada tabel 4 untuk uji paired sample test, dapat dilihat bahwa nilai sig (2-tailed) adalah 0.000 yang berarti nilai signifikan $0.000<0.05$ sehingga Ho ditolak dan Ha diterima. Dari hasil tersebut dapat disimpulkan bahwa layanan bimbingan kelompok dengan teknik permainan (game) dapat meningkatkan kecerdasan emosional siswa kelas VIII 5 SMP Negeri 18 Kota Bengkulu.

\section{Simpulan}

Berdasarkan hasil penelitian yang telah dilaksanakan pada siswa kelas VIII.5 SMP Negeri 18 Kota Bengkulu, diperoleh kesimpulan bahwa, kecerdasaan emosional siswa kelas VIII 5 SMP Negeri 18 Kota Bengkulu tergolong rendah, kecerdasan emosional siswa kelas VIII 5 SMP Negeri 18 Kota Bengkulu tergolong tinggi serta adanya penaruh bimbingan kelompok dengan teknik permainan (game) untuk meningkatkan kecerdasan emosional siswa kelas VIII 5 SMP Negeri 18 Kota Bengkulu.

Berdasarkan hasil penelitian, peneliti ingin memberikan saran yaitu, bagi peneliti selanjutnya supaya lebih mengkaji banyak sumber dan referensi mengenai kecerdasaan emosional, kemudian jika melaksanakan penelitian secara daring sebaiknya lebih memperhatikan persiapan sebelum memulai penelitian, menjadwalkan waktu sebaik mungkin agar siswa dapat hadir semua pada saat penelitian dan tidak menggangu waktu belajar siswa.

\section{Daftar Pustaka}

Amri, K., Syahniar, S., \& Nirwana, H. (2016). Peningkatan Kemampuan Mengemukakan Pendapat Melalui Layanan Bimbingan Kelompok. Konselor, 3(2), 74-80. https://doi.org/10.24036/02014323239-0-00

Hidayati, I., Mulawarman, \& Awalya. (2017). Meningkatkan regulasi emosi siswa melalui layanan bimbingan kelompok dengan teknik sosiodrama indah. Indonesian Journal of Guidance and Counseling: Theory and Application, 6(4), 27-34. Retrieved from journal.unnes.ac.id/sju/index.php/jbk

Melianasari, D. (2016). Penerapan Layanan Bimbingan Kelompok Melalui Teknik Permainan Simulasi Dan Untuk Meningkatkan Kecerdasan Emosi Siswa. Pedagogia, 14(2), 311-317. https://doi.org/10.17509/pedagogia.v14i2.3880

Pane, A., \& Darwis Dasopang, M. (2017). Belajar Dan Pembelajaran. FITRAH:Jurnal Kajian Ilmu-Ilmu Keislaman, 3(2), 333. https://doi.org/10.24952/fitrah.v3i2.945

Siegel, Sidney. (1956). Nonparametric Statistics ForThe Behavioral Sciences. New York: Mcgraw-hill book company

Sugiyono .2016. Metode Penelitian Kuantitatif, Kualitatif dan R\&D. Bandung: Alfabeta Bandung.

Susanto, N. (2017). Hakikat Dan Signifikansi Permainan. Jendela Olahraga, 
2(1), 99-104. https://doi.org/10.26877/jo.v2i1.1287

Susilowati, D. (2016). Penggunaan Layanan Bimbingan Kelompok Untuk Meningkatkan Kecerdasan Emosional Siswa Kelas VIII SMP Negeri 01 Tanjung Sari Kabupaten Lampung Selatan Tahun Pelajaran 2015/2016. Jurnal BK Lampung Selatan, 3(1), 78-89.

Lestari, I. (2012). Pengembangan Model Bimbingan Kelompok Dengan Teknik Simulasi Untuk Meningkatkan Kecerdasan Emosi Siswa. Jurnal Bimbingan Konseling, 1(2). 88-94 https://doi.org/10.15294/jubk.v1i2.685

Utama, A. M. B. (2011). Pembentukan Karakter Anak Melalui Aktivitas Bermain Dalam Pendidikan Jasmani. Pendidikan Jasmani Indonesia, 8(April), 1-9. 